\title{
PASTORAL NA UNIVERSIDADE: construindo caminhos na troca de experiências
}

\author{
Adriano Brollo ${ }^{\text {a }}$ Juliano Peroza ${ }^{\mathrm{b}}$ \\ a Graduado em Ciências Religiosas e Psicologia pela PUCPR, Coordenador de Pastoral - PUCPR, \\ Câmpus Curitiba, Assessor do Regional Sul de Pastoral das Universidades da ANEC, Curitiba, \\ PR - Brasil, e-mail: iradrianob@ marista.org.br \\ b Graduado em Filosofia pela USF, Mestrando em Educação PUCPR, Assistente de Pastoral - \\ PUCPR, Câmpus Curitiba, Curitiba, PR - Brasil, e-mail: juliano.peroza@pucpr.br
}

A justificativa e relevância da Pastoral numa Universidade seja ela confessional ou não podem ser reconhecidas no documento de João Paulo II, o qual afirma que a Universidade nasce do próprio coração da Igreja.

Nascida do coração da Igreja, a Universidade Católica insere-se no sulco da tradição que remonta à própria origem da Universidade como instituição, e revelou-se sempre um centro incomparável de criatividade e de irradiação do saber para o bem da humanidade. (JOÃO PAULO II, 2000, p. 5).

Em suas origens mais remotas a Universidade surge de um "propósito pastoral": o diálogo entre fé e razão, tendo em vista o bem comum da humanidade. No atual Documento de Aparecida (342), é feito o convite para que as Universidades Católicas fomentem o diálogo fé e razão, fé e cultura e a formação de professores, alunos e pessoal administrativo por meio, sobretudo, da Doutrina Social da Igreja, para que sejam capazes de adotar compromisso solidário com a comunidade e de testemunhar profeticamente a novidade que representa o cristianismo na vida das sociedades.

As universidades em geral, portanto, são espaços culturais e comunitários referenciais para a Igreja. Já as Universidades Católicas, ou as Instituições Confessionais Católicas de Ensino Superior em geral são, nesse 
contexto, espaços privilegiados de "pronúncia pastoral", onde o conceito de Pastoral é explicitado e amplia-se na medida em que estabelece relações significativas entre todos os setores da instituição; e na medida em que propõe a articulação entre fé, cultura, ciência e vida.

$\mathrm{Na}$ Igreja do Brasil há atualmente crescente esforço de promoção da ação pastoral nas universidades. Há ações em nível "macro", pertinentes ao âmbito de articulação nacional; e ações em nível "micro", realizadas por instituições que em seu sistema próprio administrativo contempla a ação pastoral como uma ação institucional, como identidade.

Em nível nacional, existe a articulação da CNBB, por meio do recém criado Setor Universidades, que atualmente está sob a responsabilidade de Dom Eduardo Benes, bispo auxiliar de Sorocaba. Em geral, há a promoção da Pastoral Universitária (PU), focando sempre a evangelização a partir das iniciativas dos próprios alunos. Atualmente, esse Setor possui uma assessoria que tem procurado dar maior ênfase na dinamização de um grupo de reflexão sobre o trabalho desenvolvido nas diferentes universidades com a finalidade de aglutinar experiências e enriquecer a atuação da Igreja no meio acadêmico.

A PU, portanto, é sempre uma ação eclesial e dinamizada por meio dos regionais da $\mathrm{CNBB}$ e, em comunhão com estes, por meio das várias dioceses. Em geral, o desafio maior da PU está na organização de ações articuladas entre as universidades, sobretudo nas laicas, pois estas, ao contrário das confessionais, estão desprovidas de congregações religiosas que as mantém e coordenam. Merecem, por isso, atenção missionária especial das lideranças eclesiais.

Já em níveis locais, "micros", podem-se identificar as ações realizadas pelas universidades confessionais, com uma programação própria de ação evangelizadora. A pastoral realizada nesse nível é chamada de Pastoral da Universidade (PdU). Essa é "iniciativa da própria Universidade ou faculdade, que cria um setor responsável pela animação da pastoral em seu âmbito" (ALVES, 2002, p. 123).

No entanto, a PdU realizada em Instituições Confessionais de Ensino Superior não acontece de forma isolada. Ao contrário, ela está ligada à ANEC (Associação Nacional das Escolas Católicas), que também mantém plena comunhão com a CNBB, a qual tem a pretensão de refletir a especificidade de se "fazer" pastoral numa comunidade acadêmica confessional e estabelecer comunicação e troca de experiências na "busca" de um sentido comum que 
constitua a identidade da pastoral no âmbito acadêmico. Atualmente, na ANEC existem quatro coordenadores regionais (nordeste, centro-oeste, sudeste e sul) e um coordenador nacional, que foram escolhidos no Encontro Nacional de Pastoral das Universidades, que ocorreu em Campinas, em 2007. Estes coordenadores são responsáveis pela motivação e articulação da ação pastoral nas Instituições de Ensino Superior de cada região do Brasil.

A fim de superar possíveis contradições e divisões conceituais, independente da configuração PU ou PdU, o que se deve buscar sempre é a idéia de Universidade em Pastoral, que denota a consciência de que não se evangeliza apenas nas aulas de fundamentação religiosa ou por meio de atividades especificamente religiosas confessionais, mas que toda sua estrutura (da universidade/faculdade) é evangelizadora e está comprometida com a pastoral" (ALVES, 2002, p. 12). Este termo foi fundamental para que se avançasse consideravelmente na compreensão da identidade da pastoral no ensino superior confessional, sugerindo que não basta somente haver um "núcleo" em cada instituição que fosse responsável pela execução de atividades pastorais, mas, que todo o espaço institucional deve, necessariamente, ser perpassado pelo espírito evangelizador.

\section{A experiência da PUCPR}

Neste cenário da ANEC, ao lado de outras Instituições de grande destaque na promoção de ações pastorais no âmbito universitário, insere-se a Pastoral da PUCPR. Acompanhando esta organização nacional e participando da reflexão na busca de fundamentos teológicos, filosóficos e humanistas que sejam comuns às instituições católicas do país, a Pastoral da PUCPR tenta responder às especificidades decorrentes da sua própria realidade.

Impulsionada pela Boa Nova do Evangelho, sob inspiração do carisma de Marcelino Champagnat, a pastoral na PUCPR busca envolver toda a Universidade numa atitude que supera o mero formalismo burocrático, do "dever", para uma consciência discípula e missionária que reflita este "jeito próprio de ser" Igreja no meio universitário. A partir dos documentos eclesiais e dos princípios adotados pela Província Marista do Brasil Centro Sul, recentemente, o reitor, Dr. Ir. Clemente Ivo Juliatto, lançou orientações claras 
referentes à evangelização e à pastoral nesta universidade. O referido texto, $U m$ jeito próprio de evangelizar, a pastoral na $P U C P R^{1}$ apresenta alguns pressupostos que vem sendo perseguidos pela instituição como um todo e dinamizados pelo Núcleo de Pastoral. As principais idéias e encaminhamentos pastorais da PUCPR vem sendo consolidadas e apresentamos na sequência algumas idéias referenciais que norteiam esse trabalho.

A comunidade acadêmica desta Universidade, formada por alunos, gestores, colaboradores e professores, é próspera em talentos e busca excelência na área da educação. No entanto, é complexa, dinâmica, crítica e exigente em relação à atualização dos conceitos e processos que influenciam a vida em geral. Tudo isso constitui uma realidade desafiadora para a pastoral, uma vez que esta tem a missão de harmonizar fé, cultura e vida.

Entre os colaboradores percebe-se um clima de grande abertura e sensibilidade às propostas que são feitas, porém, é preciso articulação direta junto aos gestores para facilitar a organização e viabilização das atividades. Por isso, a parceria com a DRH (Diretoria de Recursos Humanos) tem sido indispensável para o êxito e eficácia das seguintes ações pastorais: Almoço com Pastoral, Gincana Marcelino Champagnat, Na Trilha, Retiro, visita das imagens de Maria e Champagnat aos setores de trabalho, Encontros de Formação e ainda a Acolhida e explicitação da Filosofia Marista no processo de integração do colaborador à instituição.

A cátedra do professor é o areópago pastoral por excelência. Entre os professores, percebe-se senso crítico e preferência por manter relações com pessoas envolvidas em suas respectivas áreas de conhecimento. Para este público, faz-se necessário usar uma linguagem adequada e atividades que tenham relevância científica. A atividade que empreendemos e que merece destaque é o Projeto PUC Identidade, no qual os professores tem a oportunidade de refletir sobre sua práxis e aprofundar a missão institucional.

O jovem universitário desestabiliza a ação pastoral tradicional. É necessário "tirar as sandálias" para adentrar no espaço sagrado das juventudes, para isso um novo paradigma pastoral que considere a complexidade da vida universitária e da juventude se faz necessário e deve considerar a dinamicidade e multiplicidade das relações. Proximidade, agilidade e flexibilidade são

Esta expressão corresponde ao título da obra do magnífico reitor da PUCPR: JULIATTO, Clemente Ivo. Um jeito próprio de evangelizar: a pastoral na PUCPR. Curitiba: Champagnat, 2008. 
fundamentais para o êxito da atuação. Dentre as ações que despertam o interesse e a participação dos alunos merecem destaque aquelas relacionadas à ecologia, formação, solidariedade e espiritualidade.

As relações cotidianas que concretizem ad intra e ad extra o trabalho pastoral são essenciais para a eficácia da pastoral. Estas relações promovem o encontro de diferentes olhares por meio da pedagogia da presença. Nesta realidade, o Núcleo de Pastoral da PUCPR persegue o ideal de conquistar adesão de multiplicadores em todos os níveis em vista de construir uma Universidade em Pastoral.

\section{Referências}

ALVES, Vicente Paulo. Universidade em pastoral: uma nova visão sobre o jeito convencional de fazer pastoral na universidade. Petrópolis, RJ: Vozes, 2002.

CONFERÊNCIA GERAL DO EPISCOPADO LATINO-AMERICANO, 5, 2007 Aparecida do Norte, SP. Conselho Episcopal Latino-Americano. Documento de Aparecida. In: CONFERÊNCIA GERAL DO EPISCOPADO LATINO-AMERICANO E DO CARIBE, 5., 2007. São Paulo. Anais... São Paulo: Paulus, 2007.

CONSELHO EPISCOPAL LATINO-AMERICANO - CELAM. Documento de Aparecida. São Paulo: Paulinas; Paulus, 2007. n. 342.

JOÃO PAULO II. Universidades católicas. São Paulo: Paulinas, 2000.

JULIATTO, Clemente Ivo. Um jeito próprio de evangelizar: a pastoral na PUCPR. Curitiba: Champagnat, 2008.

Recebido: 10/02/2008

Received: 02/10/2008

Aprovado: 22/03/2008

Approved: 03/22/2008 